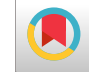

\title{
Factors Related to Type 2 Diabetes Self-Care
}

\author{
Seyyed Mohammad Taghi Ayatollahi ${ }^{1}$, Leila Malekmakan ${ }^{2}$, Mearab Sayadi (iD ${ }^{3,{ }^{*}}$ and Sadeq Karami \\ Daranjani $^{4}$ \\ ${ }^{1}$ Department of Biostatistics, School of Medicine, Shiraz University of Medical Sciences, Shiraz, Iran \\ ${ }^{2}$ Shiraz Nephro-Urology Research Center, Shiraz University of Medical Sciences, Shiraz, Iran \\ ${ }^{3}$ Cardiovascular Research Center, Shiraz University of Medical Sciences, Shiraz, Iran \\ ${ }^{4}$ Shiraz University of Medical Sciences, Shiraz, Iran \\ "Corresponding author: Cardiovascular Research Center, Shiraz University of Medical Sciences, Khalili St, Mollasdra Ave, P.O. Box: 7193635899, Shiraz, Iran. Tel: +98-9171332917, \\ Email:sayadi_me@yahoo.com
}

Received 2019 July 10; Accepted 2019 August 14.

\begin{abstract}
Background: Diabetes mellitus (DM), as a common metabolic disorder, is a manageable disease by self-care and blood sugar control. Objectives: This study was designed to investigate the factors related to diabetes self-care and control measures.

Methods: It is an analytical cross-sectional study conducted on a convenience sample of 310 type 2 DM patients referring to the centers of the Shiraz University of Medical Sciences. Self-care behavior data were collected using the self-care scale of Toobert and Glasgow from January to April 2017. Data were analyzed using SPSS and the significance level was set at $5 \%$.

Results: In this study, 310 patients with a mean age of $52.11 \pm 8.20$ were investigated (men: $n=91 ; 29.4 \%$ ). Significant relationships were observed between self-care and education level $(P=0.020)$ and job $(P=0.005)$. Also, a significant inverse relationship was observed between diabetes control and physical activity, weight management, and self-care $(\mathrm{P}<0.05)$.

Conclusions: The results showed that the education level and job could increase self-care, especially in weight management and physical activity domains; therefore, the improvement of these factors would result in better control of diabetes. In terms of job, retired people had more self-care, which could be due to their education level and having enough time for these actions.
\end{abstract}

Keywords: Diabetes Mellitus, Self-Care, Type 2 Diabetes

\section{Background}

Type 2 diabetes mellitus (T2DM) accounts for 90\% - 95\% of diabetes patients, involving 25.3 million people in the USA and 336 million all around the world (1-3). Its rate is $8 \%$ in Iran, which will involve 42.6 million people by 2030 (4). Diabetes increases the risk of many serious health problems including kidney disease, vision reduction, neuropathy, and cardiovascular disease $(5,6)$.

Diabetic patients need daily monitoring of blood sugar, injection, continuous visits with treatment staff, regular exercise, and diet programs to reach satisfying disease control. Although diabetes control and complications are costly, its acute or chronic complications can be prevented or delayed by timely diagnosis and correct care based on patient education (7-11).

Thus, controlling DM is of particular importance (12) such as methods including self-care and control of blood sugar (13). Diabetes self-care has been defined as a series of behaviors daily conducted by patients to control diabetes, such as diet adjustment, sports, medication, self- monitoring of blood sugar or urine sugar, and caring for the feet. Basic self-care has been regarded as a cure for diabetes that emphasizes changes in behaviors and management of physical, social, and economic consequences of diabetes.

Studies have shown that some factors such as social, economic, environmental, psychological, political, and cultural factors can cause serious problems for self-care processes (14-23). Although the contribution of patients plays an important role in self-care programs, not all patients comply with programs and the recognition of effective factors can help planners better design the programs.

\section{Objectives}

Therefore, this study aimed to investigate some factors affecting self-care and control measures among diabetic patients.

\section{Methods}

\subsection{Participants and Sampling}

This is a cross-sectional study performed on T2DM patients referring to the health centers of the Shiraz Univer- 
sity of Medical Sciences between January and April 2017. All patients provided informed consent before the study. The required sample size was 320 patients calculated based on approximately 50\% expected probability of self-care, $5 \%$ precision, and a 95\% confidence level and considering the infinite population that we will reach. We considered having T2DM and age $\geq 30$ years as the inclusion criteria. Patients who were pregnant or unwilling to cooperate were excluded.

\subsection{Data Collection}

Data collection was performed by one of the researchers and his coworkers in health centers. The tool was a demographic form to gather information such as age, gender, height, weight, marital status, education, job, age of disease onset, dependence on insulin, family history, blood sugar check, waist and hip circumference, and serum level of HbA1c. We also gathered the structural selfcare profiles of patients. Valid tools to evaluate the level of self-care in different aspects (nutriment, blood sugar measurement, and sports) can be found in much clinical research $(24,25)$. Here, we used the T2D self-management tool designed by Glasgow and Toobert to assess the commitment to self-care behaviors among T2DM patients. This questionnaire had 12 statements that evaluated the level of understanding and feasibility of five functions in the selfcare field (blood sugar control, receiving drugs, healthy food, physical activity, and frustration) and two overall structures (feasibility of controlling weight and reliance on the ability to manage diabetes). We used the tool to measure the level of commitment in five fields for seven days. The responses were rated from 0 to 7 and higher scores indicated higher performance of self-management activities. Then, it was rescaled to 100 for better comparison. Each domain was calculated by the sum of its items. Then, it was rescaled to 100 for better comparison. The validity and reliability of the questionnaire were established in previous studies. Content validity was tested using a panel of experts. We used factor analysis to evaluate the structure of the instrument. Internal consistency was assessed by average inter-item correlations, which was reported as acceptable (mean $=0.47)$. Test-retest correlations over 34 months were reported by the authors in the range of 0.40 to 0.78 . Its internal consistency coefficient was in the range of 0.74 to 0.78 for questions. Namdari et al. translated and confirmed the content validity and internal reli$\operatorname{ability}(\alpha=0.77)$ of this scale in Persian (24-26).

\subsection{Statistical Analysis}

Qualitative data are expressed as numbers and percentages and analyzed by the chi-square test or Fisher exact test. Quantitative data were presented as mean and standard deviation and analyzed by Pearson correlation coefficient, independent two-sample $t$-test, and one-way analysis of variance (ANOVA) with LSD post hoc test. Data were analyzed using SPSS for Windows, version 16.0. (Chicago, SPSS Inc.) at a significance level of $5 \%$.

\section{Results}

Out of 320 participants, 310 patients with complete medical records and good cooperation were enrolled in our study. Ten questionnaires were removed because of incomplete data. The mean age of the patients was $52.11 \pm$ 8.20 years (range: 30 to 65 ). Ninety-one (29.40\%) patients were men. The ratio of women to men was 2.40 . The majority of the patients were married ( $n=278,89.70 \%)$; most of them $(n=172,55.50 \%)$ had a primary education level, $110(35.50 \%)$ had secondary education to a diploma, and $28(9.00 \%)$ had university degrees. The majority of the patients ( $\mathrm{n}=196,63.20 \%)$ were housewives; 33 (10.60\%) were self-employed, 26 (8.40\%) were clerks, and 56 (18.00\%) patients were retired. Their weights varied from 35 to $110 \mathrm{~kg}$ and their 5 height varied from 138 to $191 \mathrm{~cm}$. The body max index (BMI) ranged from 14.95 to 42.42 . Waist circumference varied from 55 to $136 \mathrm{~cm}$ and their hip circumference ranged from 50 to $150 \mathrm{~cm}$. Serum HbA1C varied from 4.8 to 16.2 with a mean of $8.14 \pm 1.93$ and a median of 7.8 .

The $t$-test results are presented in Table 1 for comparing self-care scores in different domains based on gender. Based on the statistical results and the significance level obtained by the $t$-test, there were no significant differences in the mean scores of different domains of self-care between men and women.

The self-care relationship with age was measured using the Pearson correlation coefficient. The results of this analysis are summarized in Table 2. The Pearson correlation of different domains with age is given in this table. There was only a significant direct relationship between the age and the ease of blood glucose check. To investigate the relationship between self-care and level of education, we employed ANOVA with LSD post hoc test. The results of this analysis are listed in Table 3. According to the P values in this table, there was a significant difference in the self-care scores between different groups of education level. Patients with lower education levels had lower self-care scores. The LSD post hoc test indicated that this difference was related to the group under the diploma and the group with university education $(P=0.01)$. In the performance domains, just the blood sugar check domain was different among the three groups and the LSD post hoc test showed that this difference was related to the group of under diploma degrees and the group of diploma degrees $(\mathrm{P}=0.009)$. 


\begin{tabular}{|c|c|c|c|}
\hline \multirow{2}{*}{ Domains } & \multicolumn{2}{|c|}{ Gender } & \multirow{2}{*}{ P Value, $t$-test } \\
\hline & Men & Women & \\
\hline Total & $66.97 \pm 8.63$ & $66.95 \pm 8.82$ & 0.24 \\
\hline \multicolumn{4}{|l|}{ Performance } \\
\hline Receiving drugs & $91.07 \pm 14.34$ & $90.58 \pm 15.58$ & 0.79 \\
\hline Blood sugar check & $84.89 \pm 24.26$ & $82.53 \pm 25.60$ & 0.45 \\
\hline Healthy food & $76.64 \pm 16.1$ & $77.65 \pm 15.73$ & 0.611 \\
\hline Physical activity & $26.71 \pm 16.62$ & $25.39 \pm 16.21$ & 0.51 \\
\hline Frustration & $55.09 \pm 14.39$ & $54.66 \pm 14.41$ & 0.81 \\
\hline \multicolumn{4}{|l|}{ Patient behavior } \\
\hline Blood sugar check & $54.07 \pm 23.94$ & $55.89 \pm 26.25$ & 0.56 \\
\hline Receiving drugs & $61.54 \pm 24.8$ & $60.73 \pm 28.21$ & 0.81 \\
\hline Healthy food & $56.48 \pm 19.02$ & $59.29 \pm 29.33$ & 0.65 \\
\hline Physical activity & $58.09 \pm 22.77$ & $60.18 \pm 22.09$ & 0.18 \\
\hline Frustration & $65.27 \pm 24.37$ & $61.10 \pm 25.6$ & 0.25 \\
\hline Weight management & $65.71 \pm 22.76$ & $62.19 \pm 25.75$ & 0.77 \\
\hline Diabetes management & $81.27 \pm 13.15$ & $80.80 \pm 12.15$ & 0.98 \\
\hline
\end{tabular}

${ }^{\mathrm{a}}$ Values are expressed as mean $\pm \mathrm{SD}$.

\begin{tabular}{|c|c|c|}
\hline Domains & $\begin{array}{c}\text { Pearson's Correlation } \\
\text { Coefficient }\end{array}$ & P Value \\
\hline \multicolumn{3}{|l|}{ Performance } \\
\hline Receiving drugs & 0.102 & 0.07 \\
\hline Blood sugar check & 0.020 & 0.07 \\
\hline Healthy food & 0.063 & 0.26 \\
\hline Physical activity & -0.015 & 0.79 \\
\hline Frustration & -0.059 & 0.30 \\
\hline \multicolumn{3}{|l|}{ Patient behavior } \\
\hline Blood sugar check & 0.171 & 0.002 \\
\hline Receiving drugs & -0.016 & 0.78 \\
\hline Healthy food & 0.058 & 0.305 \\
\hline Physical activity & 0.052 & 0.36 \\
\hline Frustration & 0.060 & 0.25 \\
\hline $\begin{array}{l}\text { Weight } \\
\text { management }\end{array}$ & 0.045 & 0.43 \\
\hline $\begin{array}{l}\text { Diabetes } \\
\text { management }\end{array}$ & 0.027 & 0.63 \\
\hline Total & 0.078 & 0.16 \\
\hline
\end{tabular}

There was also a significant difference in the behavior domains including healthy food, physical activity, frustration, and diabetes management. The post hoc test showed that in the healthy food and physical activity domains, this difference was related to the groups with under diploma and diploma education $(\mathrm{P}=0.008$ and $\mathrm{P}=0.008$, respectively); in the frustration and diabetes management domains, this difference was related to the groups with under diploma and university education $(\mathrm{P}=0.02$ and $\mathrm{P}=0.04$, respectively).

To investigate the relationship between self-care and job, we employed ANOVA and LSD post hoc test. The results of this analysis are listed in Table 4. There was a significant difference in the self-care scores between different job groups. In the case of adaption or frustration, physical activity, consuming healthy food, and checking blood sugar in the behavior domains, there were significant differences between different job groups. There was also a significant difference in the domain of function for receiving drugs. However, the other aspects of this domain had no significant differences between different job titles. In total, the differences between the groups of housewives and retirement $(\mathrm{P}=0.02)$ and self-employment and retirement $(\mathrm{P}=$ 0.007) were significant.

The relationship between self-care and insulin use was calculated by the $t$-test. The average scores in the total domain were $67.50 \pm 9.13$ in patients who received insulin and $65.90 \pm 8.13$ in those who $\operatorname{did} \operatorname{not}(\mathrm{P}=0.110$ and $t=1.57)$. According to Table 5, there was a significant inverse relationship between self-care score and HbA1c so that those with higher self-care scores had lower HbA1c levels and 


\begin{tabular}{|c|c|c|c|c|}
\hline \multirow{2}{*}{ Domains } & \multicolumn{3}{|c|}{ Education Level } & \multirow{2}{*}{ P Value, ANOVA } \\
\hline & Under Diploma & Diploma & University & \\
\hline Total & $65.85 \pm 9.06$ & $67.67 \pm 8.54$ & $70.14 \pm 6.89$ & 0.02 \\
\hline \multicolumn{5}{|l|}{ Performance } \\
\hline Receiving drugs & $90.0 \pm 15.67$ & $90.91 \pm 14.35$ & $90.18 \pm 16.08$ & 0.97 \\
\hline Blood sugar check & $86.19 \pm 21.75$ & $78.18 \pm 29.05$ & $84.82 \pm 26.43$ & 0.03 \\
\hline Healthy food & $78.7 \pm 14.88$ & $75.45 \pm 16.12$ & $76.56 \pm 19.33$ & 0.23 \\
\hline Physical activity & $24.78 \pm 15.85$ & $26.64 \pm 16.76$ & $28.55 \pm 17.48$ & 0.41 \\
\hline Frustration & $55.16 \pm 4.34$ & $53.84 \pm 4.72$ & $56.19 \pm 13.38$ & 0.65 \\
\hline \multicolumn{5}{|l|}{ Patient behavior } \\
\hline Blood sugar check & $54.3 \pm 24.80$ & $58.55 \pm 26.77$ & $49.29 \pm 24.63$ & 0.16 \\
\hline Receiving drugs & $58.84 \pm 27.75$ & $62.73 \pm 26.19$ & $67.16 \pm 27.33$ & 0.23 \\
\hline Healthy food & $55.81 \pm 18.36$ & $62.06 \pm 20.72$ & $60.71 \pm 16.48$ & 0.02 \\
\hline Physical activity & $56.98 \pm 22.89$ & $64.18 \pm 21.12$ & $60 \pm 21.08$ & 0.02 \\
\hline Frustration & $60.70 \pm 25.58$ & $62.36 \pm 25.23$ & $72.14 \pm 24.22$ & 0.04 \\
\hline Weight management & $61.16 \pm 24.53$ & $65.09 \pm 25.62$ & $68.57 \pm 23.99$ & 0.21 \\
\hline Diabetes management & $79.43 \pm 13.22$ & $82.31 \pm 13.80$ & $84.82 \pm 11.06$ & 0.04 \\
\hline
\end{tabular}

\footnotetext{
${ }^{\mathrm{a}}$ Values are expressed as mean $\pm \mathrm{SD}$.
}

\begin{tabular}{|c|c|c|c|c|c|}
\hline \multirow{2}{*}{ Domains } & \multicolumn{4}{|c|}{ Job } & \multirow{2}{*}{ P Value, ANOVA } \\
\hline & Housewife & Clerk & Free Job $^{\text {b }}$ & Retired & \\
\hline Total & $66.46 \pm 8.63$ & $66.39 \pm 6.82$ & $63.91 \pm 8.32$ & $70.28 \pm 9.56$ & 0.005 \\
\hline \multicolumn{6}{|l|}{ Performance } \\
\hline Receiving drugs & $89.86 \pm 16.16$ & $95.67 \pm 8.61$ & $84.77 \pm 17.16$ & $94.87 \pm 10.6$ & 0.006 \\
\hline Blood sugar check & $82.84 \pm 25.02$ & $87.5 \pm 25.98$ & $85.94 \pm 18.17$ & $81.03 \pm 28.89$ & 0.66 \\
\hline Healthy food & $77.23 \pm 15.89$ & $78.84 \pm 20.46$ & $75.97 \pm 10.77$ & $77.90 \pm 15.89$ & 0.90 \\
\hline Physical activity & $24.97 \pm 16.65$ & $32.00 \pm 14.85$ & $23.97 \pm 17.41$ & $26.76 \pm 14.78$ & 0.18 \\
\hline Frustration & $54.61 \pm 14.35$ & $56.15 \pm 5.22$ & $53.54 \pm 2.26$ & $55.47 \pm 15.47$ & 0.89 \\
\hline \multicolumn{6}{|l|}{ Patient behavior } \\
\hline Blood sugar check & $55.20 \pm 25.61$ & $43.85 \pm 21.18$ & $49.75 \pm 21.51$ & $65.00 \pm 26.49$ & 0.001 \\
\hline Receiving drugs & $59.80 \pm 27.91$ & $56.15 \pm 24.01$ & $56.25 \pm 22.39$ & $70.00 \pm 27.23$ & 0.03 \\
\hline Healthy food & $58.7 \pm 15.02$ & $54.10 \pm 17.31$ & $51.45 \pm 18.41$ & $63.69 \pm 20.17$ & 0.02 \\
\hline Physical activity & $59.39 \pm 21.9$ & $60 \pm 21.90$ & $50.62 \pm 20.93$ & $66.43 \pm 22.91$ & 0.01 \\
\hline Frustration & $60.82 \pm 25.04$ & $66.92 \pm 21.86$ & $58.12 \pm 26.08$ & $67.86 \pm 26.60$ & 0.16 \\
\hline Weight management & $61.53 \pm 25.45$ & $63.08 \pm 21.68$ & $59.38 \pm 21.24$ & $71.43 \pm 25.25$ & 0.05 \\
\hline Diabetes management & $80.46 \pm 13.04$ & $79.80 \pm 12.83$ & $79.03 \pm 12.98$ & $84.22 \pm 12.7$ & 0.19 \\
\hline
\end{tabular}

\footnotetext{
${ }^{\mathrm{a}}$ Values are expressed as mean $\pm \mathrm{SD}$.
}

${ }^{\mathrm{b}}$ Free job, self-employment.

whose diabetes is under control.

\section{Discussion}

Self-care programs constitute more than $90 \%$ of blood sugar control programs in T2DM. Environmental and social factors stopped $85 \%$ of diabetic patients from following their care behaviors $(27,28)$. Some factors can influ- ence self-care and diabetes control $(28,29)$, the identification of which can resolve the problems and help the educators of self-care programs take more effective measures for DM control and complication prevention. Therefore, the present study aimed to determine the factors related to self-care and disease control in diabetic patients.

In this study, we showed that social factors such as job and education level could influence the self-care and 


\begin{tabular}{|c|c|c|}
\hline Domains & $\begin{array}{c}\text { Pearson's Correlation } \\
\text { Coefficient }\end{array}$ & P Value \\
\hline \multicolumn{3}{|l|}{ Performance } \\
\hline Receiving drugs & -0.033 & 0.58 \\
\hline Blood sugar check & -0.030 & 0.61 \\
\hline Healthy food & 0.002 & 0.96 \\
\hline Physical activity & 0.018 & 0.76 \\
\hline Frustration & 0.104 & 0.08 \\
\hline \multicolumn{3}{|l|}{ Patient behavior } \\
\hline Blood sugar check & -0.199 & 0.001 \\
\hline Receiving drugs & -0.069 & 0.25 \\
\hline Healthy food & -0.064 & 0.28 \\
\hline Physical activity & -0.008 & 0.88 \\
\hline Frustration & -0.112 & 0.06 \\
\hline $\begin{array}{l}\text { Weight } \\
\text { management }\end{array}$ & -0.079 & 0.18 \\
\hline $\begin{array}{l}\text { Diabetes } \\
\text { management }\end{array}$ & -0.151 & 0.01 \\
\hline Total & -0.133 & 0.02 \\
\hline
\end{tabular}

diabetes control behaviors. In terms of job, the highest score of self-care belonged to retired people. This can be attributed to several reasons such as having a constant income and more free time. Regarding the level of education, as previous studies showed, people with higher education levels had higher self-care scores and their diabetes was more under control $(14,30)$. Therefore, it can be said that having job security and enough time for the management of diabetes are the basic needs for reducing stress in patients, which facilitates diabetes control behaviors more effectively.

This study, like previous studies, indicated a significant inverse relationship between self-management and serum HbA1C (31, 32). However, an inverse interpretation can be made; patients with lower HbA1C have better physical and psychological health. Also, for justification of HbA1C correlation with diabetes self-management, it must be noted that probably those with higher self-management achieved in controlling diabetes; therefore, they will have lower HbA1C. For obtaining better life quality, diabetic patients should follow their self-care programs, which include diet, regular exercise, regular blood sugar tests, drug follow-up, and caring for the feet (33).

Socioeconomic condition is a combinational index of education level and income. People normally respond more reliably to questions about their jobs and education. In many countries including Iran, the response to income is not real and the best method for measuring this index is controversial. Therefore, in this study, although these data were collected, due to the unreliability of the data, information regarding the economic level was not used in the statistical analysis.

The social condition can reflect economic conditions. However, in some rare cases, economic condition is not a function of social situation. In some studies, economic beside social conditions revealed that social factors such as economic-social ones were significantly associated with diabetes, self-care, and related consequences. They also showed that DM complications were related to high economic and social conditions and high self-efficiency, as well.

Similar studies also revealed that low social class and low education levels could result in higher number of deaths and more rates of diabetes $(34,35)$.

The education level also reflects the economic condition and can be regarded as a basis for the inequities in receiving health services and thus having a bad general health condition. In this study, similar to others, education affected self-care and diabetes control. In recent decades, interest has increased in health knowledge for collecting enough evidence about personal disease control by self-care. Health knowledge can increase the personal responsiveness and ability of people to manage the disease through self-care $(36,37)$. Previous studies showed that people with high socioeconomic class preferred private health centers to public ones (38).

Data collection tools were reliable and accurate; however, there were some weaknesses, as well. This study was only conducted in public centers whose referring patients were not from various social and economic classes. Therefore, it is proposed to consider this point and design research on diabetic patients of public and private health centers or change the sampling method in a way that this drawback could be removed.

\subsection{Conclusions}

The results showed that the education level and the job could increase diabetes self-care, especially in weight management and physical activity. Therefore, the improvement of these factors will result in better control of diabetes. In terms of job, retired people had more self-care, which could be due to their education level and having enough time for doing these actions.

\section{Acknowledgments}

We would like to appreciate the cooperation of the non-communicable diseases unit of Vice-Chancellor for Health of Shiraz University of Medical Sciences. The authors would like to thank the Center for Development of 
Clinical Research of Nemazee Hospital and Dr. Nasrin Shokrpour for editorial assistance.

\section{Footnotes}

Authors' Contribution: Study concept and design: Mearab Sayadi and Leila Malekmakan. Analysis and interpretation of data: Seyyed Mohammad Taghi Ayatollahi. Drafting of the manuscript: Seyyed Mohammad Taghi Ayatollahi, Leila Malekmakan, Mearab Sayadi, and Sadeq Karami Daranjani.

Conflict of Interests: The authors declare that they have no conflicts of interest regarding the publication of this paper.

Ethical Approval: The study was confirmed by the ViceChancellery for Research and Technology (approval cod 9616337).

Funding/Support: The Vice-Chancellery of Research and Technology of Shiraz University of Medical Sciences supported this study (grant number: 16337).

\section{References}

1. Sultan S, Attali C, Gilberg S, Zenasni F, Hartemann A. Physicians' understanding of patients' personal representations of their diabetes: Accuracy and association with self-care. Psychol Health. 2011;26 Suppl 1:101-17. doi: 10.1080/08870441003703226. [PubMed: 21337260].

2. Moons KG, Altman DG, Vergouwe Y, Royston P. Prognosis and prognostic research: Application and impact of prognostic models in clinical practice. BMJ. 2009;338:b606. doi: 10.1136/bmj.b606. [PubMed: 19502216].

3. Dafni U. Landmark analysis at the 25-year landmark point. Circ Cardiovasc Qual Outcomes. 2011;4(3):363-71. doi: 10.1161/CIRCOUTCOMES.110.957951. [PubMed: 21586725].

4. WHO. Diabetes action now: An initiative the International Diabetes Federation. 2004. Available from: http://apps.who.int/iris/bitstream/ handle/10665/42934/924159151X.pdf?sequence $=1$.

5. Home PD. Impact of the UKPDS-an overview. Diabet Med. 2008;25 Suppl 2:2-8. doi: 10.1111/j.1464-5491.2008.02501.x. [PubMed: 18717971]

6. Alvarez EO, Beauquis J, Revsin Y, Banzan AM, Roig P, De Nicola AF, et al. Cognitive dysfunction and hippocampal changes in experimental type 1 diabetes. Behav Brain Res. 2009;198(1):224-30. doi: 10.1016/j.bbr.2008.11.001. [PubMed:19041902]

7. Sabatier R, Eymard JC, Walz J, Deville JL, Narbonne H, Boher JM, et al. Could thyroid dysfunction influence outcome in sunitinib-treated metastatic renal cell carcinoma? Ann Oncol. 2012;23(3):714-21. doi: 10.1093/annonc/mdr275. [PubMed: 21653681].

8. Khaw KT, Wareham N, Bingham S, Luben R, Welch A, Day N. Association of hemoglobin A1c with cardiovascular disease and mortality in adults: The European prospective investigation into cancer in Norfolk. Ann Intern Med. 2004;141(6):413-20. doi: 10.7326/0003-4819-141-6 200409210-00006. [PubMed: 15381514]

9. Zheng J, Cheng J, Zhang Q, Qi C, Wang T, Xiao X. Association between glycosylated hemoglobin level and cardiovascular outcomes in diabetic patients after percutaneous coronary intervention. Medicine (Baltimore). 2016;95(19). e3696. doi: 10.1097/MD.0000000000003696. [PubMed: 27175711]. [PubMed Central: PMC4902553].
10. Monahan F, Sands J, Neighbors M, Marek J, Green-Nigro C. Phipps' medical-surgical nursing: Health and illness perspectives. 8th ed. Philadelphia: Elsevier Mosby; 2007.

11. Khamseh M, Monavari A, Malek M, Shafiee G, Baradaran H. [Healthrelated quality of life in patients with type 1 diabetes]. Iran JEndocrinol Metab. 2011;13(3):249-56. Persian.

12. Saadatjoo SA, Rezvanee MR, Tabyee SH, Oudi D. [Life quality comparison in type 2 diabetic patients and none diabetic persons]. Mod Care J. 2012;9(1):24-31. Persian.

13. Ratner R, Goldberg R, Haffner S, Marcovina S, Orchard T, Fowler S, et al. Impact of intensive lifestyle and metformin therapy on cardiovascular disease risk factors in the diabetes prevention program. Diabetes Care. 2005;28(4):888-94. doi: 10.2337/diacare.28.4.888. [PubMed 15793191]. [PubMed Central: PMC1307521].

14. Alberti H, Boudriga N, Nabli M. Factors affecting the quality of diabetes care in primary health care centres in Tunis. Diabetes Res Clin Pract. 2005;68(3):237-43. doi: 10.1016/j.diabres.2004.09.016. [PubMed: 15936466].

15. Rubin RR, Peyrot M, Siminerio LM. Health care and patient-reported outcomes: Results of the cross-national Diabetes Attitudes, Wishes and Needs (DAWN) study. Diabetes Care. 2006;29(6):1249-55. doi 10.2337/dc05-2494. [PubMed: 16732004].

16. Sarkar U, Fisher L, Schillinger D. Is self-efficacy associated with diabetes self-management across race/ethnicity and health literacy? $\mathrm{Di}$ abetes Care.2006;29(4):823-9. doi:10.2337/diacare.29.04.06.dc05-1615. [PubMed: 16567822].

17. Bandura A. Health promotion by social cognitive means. Health Educ Behav. 2004;31(2):143-64. doi: 10.1177/1090198104263660. [PubMed: 15090118].

18. Brown AF, Ettner SL, Piette J, Weinberger M, Gregg E, Shapiro MF, et al. Socioeconomic position and health among persons with diabetes mellitus: A conceptual framework and review of the literature. Epidemiol Rev. 2004;26:63-77. doi: 10.1093/epirev/mxh002. [PubMed 15234948].

19. Baquedano IR, dos Santos MA, Teixeira CR, Martins TA, Zanetti ML. [Factors related to self-care in diabetes mellitus patients attended at emergency service in Mexico]. Rev Esc Enferm USP. 2010;44(4):101723. Portuguese. doi: 10.1590/s0080-62342010000400023. [PubMed: 21337785].

20. Friel S, Marmot MG. Action on the social determinants of health and health inequities goes global. Annu Rev Public Health. 2011;32:225-36. doi: 10.1146/annurev-publhealth-031210-101220. [PubMed: 21219162].

21. Bonnefoy J, Morgan A, Kelly MP, Butt J, Bergman V. Constructing the evidence base on the social determinants of health: A guide. Meas Evidence Knowl Network. 2007.

22. Agardh E, Allebeck P, Hallqvist J, Moradi T, Sidorchuk A. Type 2 diabetes incidence and socio-economic position: A systematic review and meta-analysis. Int J Epidemiol. 2011;40(3):804-18. doi 10.1093/ije/dyro29. [PubMed: 21335614]

23. Walker RJ, Smalls BL, Campbell JA, Strom Williams JL, Egede LE. Impact of social determinants of health on outcomes for type 2 diabetes: A systematic review. Endocrine. 2014;47(1):29-48. doi: 10.1007/s12020014-0195-0. [PubMed: 24532079].

24. Toobert DJ, Hampson SE, Glasgow RE. The summary of diabetes selfcare activities measure: Results from 7 studies and a revised scale. Dia betes Care. 2000;23(7):943-50. doi: 10.2337/diacare.23.7.943. [PubMed: 10895844]

25. Toobert DJ, Glasgow RE. Assessing diabetes self-management: The summary of Diabetes Self-Care Activities questionnaire. In: Bradley C\&gt;, editor. Handbook of psychology and diabetes: A guide to psychological measurement in diabetes research and practice. 1994. p. 351-75.

26. Ghasemi N, Namdari K, Ghoreshian M, Amini M. The relationship between "expectationism" and "loyalty to self-care behaviors" in type Il diabetes patients. Sci J Clin Psychol Pers. 2010;1(43):1-10.

27. Asante E. Interventions to promote treatment adherence in type 2 diabetes mellitus. Br J Community Nurs. 2013;18(6):267-74. doi 10.12968/bjcn.2013.18.6.267. [PubMed: 24046923]. 
28. Kollannoor-Samuel G, Vega-Lopez S, Chhabra J, Segura-Perez S, Damio G, Perez-Escamilla R. Food insecurity and low self-efficacy are associated with health care access barriers among Puerto-Ricans with type 2 diabetes.JImmigr Minor Health. 2012;14(4):552-62. doi: 10.1007/s10903011-9551-9. [PubMed: 22101725]. [PubMed Central: PMC3389151].

29. Berkowitz SA, Baggett TP, Wexler DJ, Huskey KW, Wee CC. Food insecurity and metabolic control among U.S. adults with diabetes. Diabetes Care. 2013;36(10):3093-9. doi: 10.2337/dc13-0570. [PubMed: 23757436] [PubMed Central: PMC3781549].

30. Siebolds M, Gaedeke O, Schwedes U; Smbg Study Group. Selfmonitoring of blood glucose-psychological aspects relevant to changes in HbA1c in type 2 diabetic patients treated with diet or diet plus oral antidiabetic medication. Patient Educ Couns. 2006;62(1):10410. doi:10.1016/j.pec.2005.06.013. [PubMed:16159705].

31. Persell SD, Keating NL, Landrum MB, Landon BE, Ayanian JZ, Borbas C, et al. Relationship of diabetes-specific knowledge to self-management activities, ambulatory preventive care and metabolic outcomes. Prev Med. 2004;39(4):746-52. doi 10.1016/j.ypmed.2004.02.045. [PubMed: 15351541].

32. Xu Y. Understanding the factors influencing diabetes self-management in Chinese people with type 2 diabetes using structural equation modeling. Ohio: University of Cincinnati; 2005.
33. Shrivastava SR, Shrivastava PS, Ramasamy J. Role of self-care in management of diabetes mellitus. J Diabetes Metab Disord. 2013;12(1):14. eng. doi: 10.1186/2251-6581-12-14. [PubMed: 23497559].

34. Whiting D, Unwin N, Roglic G. Diabetes: Equity and social determinants. Equity, Social Determinants and Public Health programmes. WHO; 2010. Available from: http://www.who.int/sdhconference/resources/ EquitySDandPH_eng.pdf\#page $=87$.

35. Saydah S, Lochner K. Socioeconomic status and risk of diabetesrelated mortality in the U.S. Public Health Rep. 2010;125(3):377-88. doi: 10.1177/003335491012500306. [PubMed: 20433032]. [PubMed Central: PMC2848262].

36. Berkman ND, Sheridan SL, Donahue KE, Halpern DJ, Crotty K. Low health literacy and health outcomes: An updated systematic review. Ann Intern Med. 2011;155(2):97-107. doi: 10.7326/0003-4819-155-2201107190-00005. [PubMed: 21768583].

37. Sayadi M, Zibaeenezhad M, Taghi Ayatollahi SM. Simple prediction of type 2 diabetes mellitus via decision tree modeling. Int Cardiovasc Res J. 2017;11(2).

38. Malek Makan L, Moghadami M, Sayadi M, Mahdavi Azad H, Alipouri Sakha M. [Assessment of social determinants related to mother and child healthcare services: A cross sectional study in Shiraz, Iran 2013]. Shiraz E-Med J. 2015;16(5). Persian. e26726. doi:10.17795/semj26726. 